\title{
Size dependent conduction characteristics of catalyst- multi-walled carbon nanotube junction
}

\section{Chris J. Barnett ${ }^{1}$ • Alvin Orbaek White ${ }^{1}$ Andrew R. Barron ${ }^{1,2,3}$}

$\bowtie$ Chris J. Barnett c.j.barnett@swansea.ac.uk

$\bowtie$ Alvin Orbaek White alvin.orbaekwhite@swansea.ac.uk

$\bowtie$ Andrew R. Barron a.r.barron@swansea.ac.uk

1 Energy Safety Research Institute, Swansea University Bay Campus, Swansea SA1 8EN, UK

2 Department of Chemistry and Department of Materials Science and Nanoengineering, Rice University, Houston, Texas 77005, USA

3 Faculty of Engineering, Universiti Teknologi Brunei, Jalan Tungku Link, Gadong, BE1410, Brunei Darussalam

\begin{abstract}
Multi-walled carbon nanotubes (MWCNTs) grown by chemical vapor deposition retain the residual catalyst particles from which the growth occurred, which are considered a detriment to MWCNTs performance, especially electrical conductivity. The first direct measurements have been made of the electrical transport through the catalyst cap into the MWCNT using nanoscale 2-point-probe to determine the effects of the catalyst particle's size and the diameter ratio with its associated MWCNT on the electrical transport through the catalyst cap as compared the inherent conductivity of the MWCNT. The MWCNT diameter is independent of the catalyst size, but the ratio of the catalyst cap diameter to MWCNT diameter $\left(\mathrm{D}_{\mathrm{C}} / \mathrm{D}_{\mathrm{NT}}\right)$ determines the conduction mechanism. Where $\mathrm{D}_{\mathrm{C}} / \mathrm{D}_{\mathrm{NT}}$ is greater than 1 the resulting $\mathrm{I}-\mathrm{V}$ curve is near ohmic, and the conduction through the catalyst $\left(\mathrm{R}_{\mathrm{C}+\mathrm{NT}}\right)$ approaches that of the MWCNT $\left(\mathrm{R}_{\mathrm{NT}}\right)$; however, when the $\mathrm{D}_{\mathrm{C}} / \mathrm{D}_{\mathrm{NT}}<1$ the I-V curves shifts to rectifying and $\mathrm{R}_{\mathrm{C}+\mathrm{NT}}>\mathrm{R}_{\mathrm{NT}}$. The experimental results are discussed in relation to current crowding at the interface between catalyst and nanotube due to an increased electric field.
\end{abstract}

Keywords Multi-walled carbon nanotubes - Catalyst - Electrical conductivity - Contact resistance $\cdot$ Nanoprobe 


\section{Submitted to Carbon Letters}

\section{Introduction}

The most common method for the growth of carbon nanotubes (CNTs) involves exposure of a metal catalysts particle to a carbon containing source gas such as $\mathrm{CO}$, methane or higher hydrocarbon [1,2]. Upon isolation of the CNTs the residual catalyst particles remain attached, in particular on the end (rather than sidewall) of the CNT. This is particularly true for larger multi-walled carbon nanotubes (MWCNTs) that are fed with carbon during growth via their tips which support the catalyst particle [3]. Since the catalyst residue is considered an impurity, there are a wide range of approaches for its removal [4-7]; however, they offer a potential route to the study of metal-CNT interfacial properties.

The electronic properties of CNTs offer potential device application [8] and that at the nanoscale contact-resistance and electron-transport across material interfaces can dominate the system properties. Depending on the devices application this can either be a problem or a benefit and therefore understanding the electron transport across interfaces is of great importance. We have recently explored the experimental effects of the metal identity in metal $\cdots$ CNT contacts onto the side walls of the CNTs [9]. These results demonstrated the importance of the identity of the metal in the creation of a low resistance junctions and supported prior computational results [10]. Although similar trend was calculated for end contacts (i.e., between a metal electrode and the end of the CNT) there have been no measurements of the effect of the size of a metal contact with the end of a CNT on the electrical resistance of the junction.

We have developed methodology to allow accurate repeatable measurements of conductivity of individual CNTs as a function of distance and orientation $[11,12]$, and have employed these methods to measure the junction resistance between a metal catalyst particle and the end of a CNT as a function of the diameter of the metal particle $\left(\mathrm{D}_{\mathrm{C}}\right)$.

\section{Experimental}

MWCNTs were synthesized in table-top horizontal tube reactor at $750{ }^{\circ} \mathrm{C}$ with a toluene carbon source and ferrocene $\left[\mathrm{Fe}\left(\mathrm{C}_{5} \mathrm{H}_{5}\right)_{2}\right]$ as an iron catalyst [2]. The as prepared MWCNTs were processed using a microwave to remove most of the iron catalyst residue [4] and handled as previously described [13]. The nanotubes were then suspended in ethanol and drop cast on to a silicon wafer with native oxide with a resistance at least 3 orders of magnitude higher $\left(10^{-9}\right.$ $\Omega)$ than that of the MWCNT [11].

The sample was placed in an Omicron LT Nanoprobe equipped with SEM column (base pressure $1 \times 10^{-11} \mathrm{mbar}$ ) and annealed to $500{ }^{\circ} \mathrm{C}$ for hour to remove surface contamination 
which can influence electrical measurements [11]. The two-point probe measurements were carried out using tungsten STM probes that were etched in $2 \mathrm{M} \mathrm{KOH}$ solution [14] and direct current annealed in vacuum to remove shank oxide to ensure consistent contacts $[15,16]$. It is known that the probes can induce strain on samples if approach in too large increments, therefore the tips were approach is $0.1 \mathrm{~nm}$ increments until in contact to minimize strain induced resistance change using the method described previously [17]. The two-point probe measurements were carried out on ten different nanotube with one tip landed on the MWCNT away from the catalyst cap and the second probe was landed on the cap, measurements taken then retract and landed on the nanotube close to the cap. The five current measurements at each tip position was averaged and the resistance calculated at $-1 \mathrm{~V}$. The deviation between the five measures shows at that $-1 \mathrm{~V}$ to $1 \mathrm{~V}$ sweep did not alter the nanotube via direct current annealing.

\section{Results and discussion}

As measured by the Omicron Nanoprobe SEM, the as grown MWCNTs had diameters $\left(\mathrm{D}_{\mathrm{NT}}\right)$ that varied from $89 \mathrm{~nm}$ to $150 \mathrm{~nm}$ with catalyst caps diameters $\left(\mathrm{D}_{\mathrm{C}}\right)$ that varied from $51 \mathrm{~nm}$ to $288 \mathrm{~nm}$ (Table 1). A typical Raman spectra collected using a $532 \mathrm{~nm}$ laser from a Renshaw spectroscope, from three areas of the sample with $10 \mathrm{~s}$ integration time, with a laser power of $1.7 \mathrm{~mW}$, accumulated 3 time from taken from these nanotubes is shown in Fig. 1. It has been previously proposed that the diameters of CNTs are proportional to the size of the catalyst used in the growth process [18-20], but we have previously demonstrated that with regard to single walled carbon nanotubes (SWCNTs) large catalysts $(8-9 \mathrm{~nm})$ allow for the growth of SWNTs with diameters comparable to prior results with 1-3 nm diameter catalysts [21]. Examples of catalyst caps both smaller and larger than the MWCNT's diameter are shown in Fig. 2.

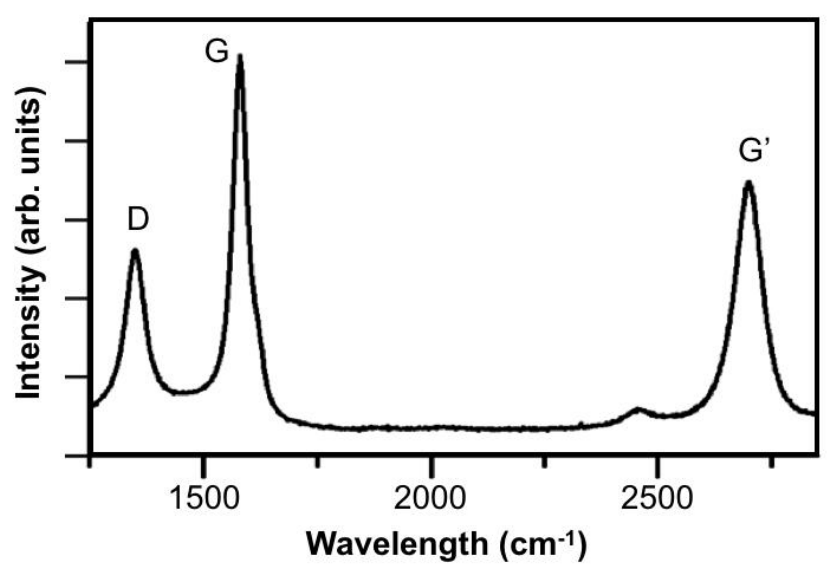

Fig. 1 Raman spectrum of multi walled carbon nanotube after argon bombardment. 




Fig. 2 Typical SEM image of MWCNTs used in the present study with catalysts with diameters smaller than tube diameter (red squares, $\mathrm{D}_{\mathrm{C}} / \mathrm{D}_{\mathrm{NT}}<1$ ) and catalyst diameter larger than tube diameter (green circles, $\mathrm{D}_{\mathrm{C}} / \mathrm{D}_{\mathrm{NT}}>1$ ).

As may be seen from Fig. 3a, in the present case there is no correlation between MWCNT diameter and cap diameter. This is in contrast to work by Leiber and co-workers [20]; however, in their work the MWCNTs were grown using surface supported catalyst particles, whereas the MWCNTs studied herein are grown in the vapor phase. Based upon Fig. 3a it appears that under the specific temperature and reagent conditions used, vapor phase grown MWCNTs are grown with a relatively narrow diameter range irrespective of the catalyst size. This deviation from the expected relationship [20] is possibly due the diameter being controlled by reagent supply during the short residence time in the growth zone. The relatively constant $\mathrm{D}_{\mathrm{NT}}$ is further demonstrated by the near linear relationship between $\mathrm{D}_{\mathrm{C}}$ and the $\mathrm{D}_{\mathrm{C}} / \mathrm{D}_{\mathrm{NT}}$ ratio (Fig. 3b).

Table 1 Diameter (D) of MWCNTs and catalyst caps and electrical resistance (R), calculated at $-1 \mathrm{~V}$, through the MWCNTs and through the catalyst cap and the MWCNTs.

\begin{tabular}{cccc}
\hline $\mathrm{D}_{\mathrm{NT}}(\mathrm{nm})$ & $\mathrm{D}_{\mathrm{C}}(\mathrm{nm})$ & $\mathrm{R}_{\mathrm{NT}}(\mathrm{k} \Omega)$ & $\mathrm{R}_{\mathrm{C}+\mathrm{NT}}(\mathrm{k} \Omega)$ \\
\hline 119 & 288 & $24.9 \pm 0.24$ & $31.5 \pm 1.1$ \\
94 & 51 & $2,030 \pm 121$ & $15,500 \pm 206$ \\
147 & 303 & $177 \pm 15.2$ & $221 \pm 6.4$ \\
117 & 180 & $25.7 \pm 0.47$ & $38.1 \pm 1.2$
\end{tabular}




$\begin{array}{cccc}124 & 147 & 571 \pm 60.8 & 1260 \pm 4.3 \\ 113 & 95 & 67.2 \pm 10.9 & 3180 \pm 446 \\ 108 & 101 & 17.0 \pm 0.15 & 125 \pm 0.3 \\ 150 & 101 & 22.0 \pm 0.54 & 412 \pm 4.1 \\ 126 & 68 & 20.1 \pm 0.23 & 465 \pm 24.1 \\ 89 & 95 & 8.38 \pm 0.03 & 20.9 \pm 0.15\end{array}$

(a)

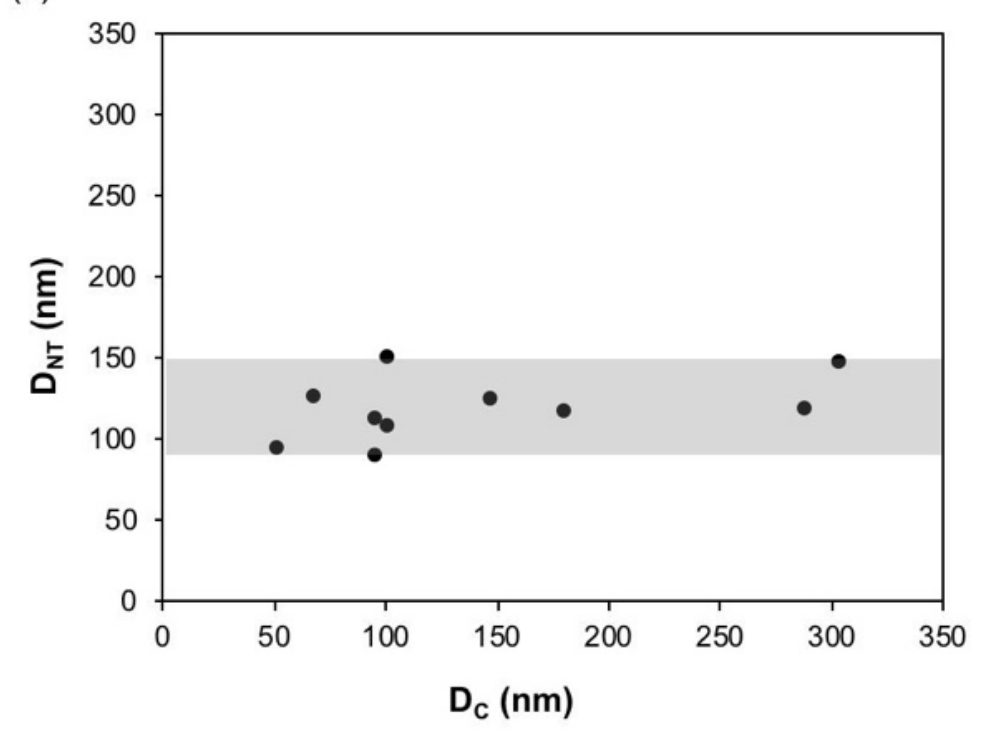

(b)

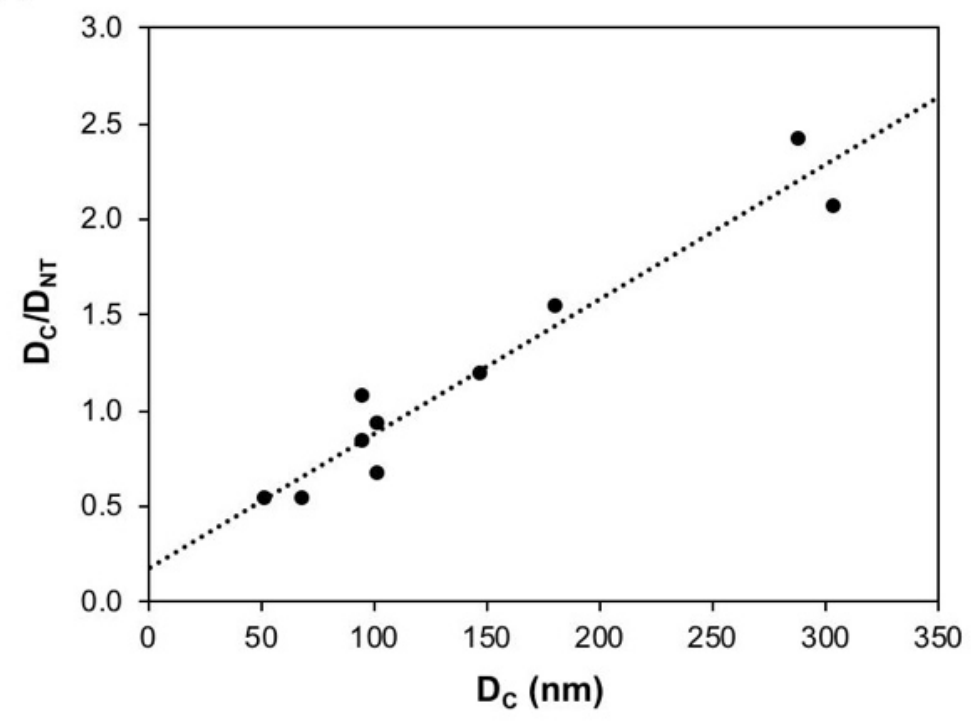

Fig. 3 Plot of (a) the diameter of the MWCNTs $\left(D_{\mathrm{NT}}\right)$ versus the diameter of the catalyst caps $\left(D_{C}\right)$ and $(b)$ the diameter ratio $\left(D_{C} / D_{N T}\right)$ versus catalyst caps $\left(D_{C}\right)\left(R^{2}=0.94\right)$. 
Two point probe I-V measurements were carried out on 10 different nanotube with one tip landed on the MWCNT away from the catalyst cap and the second probe was landed on the cap, measurements taken then retract and landed on the nanotube close to the cap, which can be seen in Fig. 4. Since it was not possible to always find isolated MWCNTs with the necessary range of tube and catalyst on the tip, some measures were taken on a tube that was crossed by another MWCNT (see Fig. 4c and d); however, our previous work has shown such crossing point do not significantly alter the resistance measures of a nanotube providing the tip are not positions close to a crossing point [12]. Therefore, as show in Fig. $4 \mathrm{c}$ and $\mathrm{d}$ the nanoprobe tips were positioned away from crossing tubes.

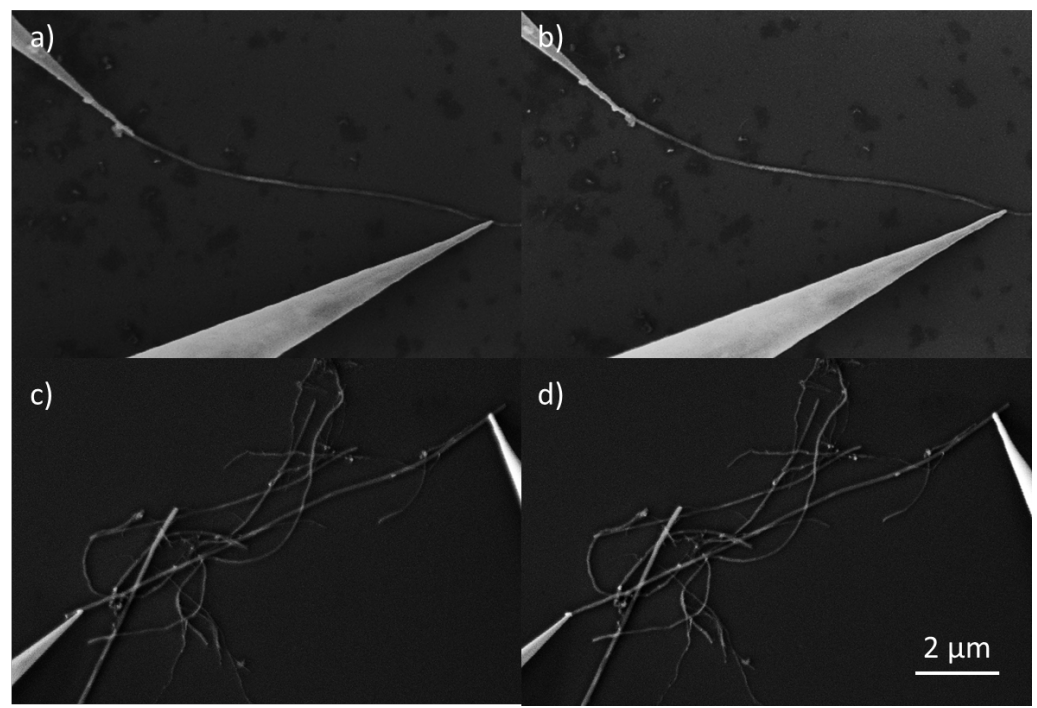

Fig. 4 SEM images of (a) both tips on a MWCNT in isolation, (b) one tip on a MWCNT and one tip on catalyst cap which is large in diameter than the MWCNT, (c) both tips on a MWCNT that is crossed by other MWCNTs and (d) one tip on MWCNT and one tip on catalyst cap which is smaller in diameter than the MWCNT.

For each measurement, the voltage was swept be $-1 \mathrm{~V}$ and $1 \mathrm{~V}$, and five repeat measurements were taken and during measurement the SEM beam as switched off to ensure electron bean does not affect the IV measurements. Resistance measures through just the nanotube will be referred hereafter as $\mathrm{R}_{\mathrm{NT}}$ and resistance measurement through catalyst and nanotube as $\mathrm{R}_{\mathrm{C}+\mathrm{NT}}$. The majority of the nanotubes had an $\mathrm{R}_{\mathrm{NT}}$ of the order of $10^{4} \Omega$, Table 1 , which is in agreement to our previous results on similar MWCNTs [11,12]. The resistance measurement through catalyst and nanotube $\left(\mathrm{R}_{\mathrm{C}+\mathrm{NT}}\right)$ are all statistically greater than the values for the same nanotube $\left(\mathrm{R}_{\mathrm{NT}}\right)$; however, while in some cases, the increase is resistance is small 
and the overall values are of same order of magnitude, in many case $\mathrm{R}_{\mathrm{C}+\mathrm{NT}}$ is over an order of magnitude high that $\mathrm{R}_{\mathrm{NT}}$. The difference between $\mathrm{R}_{\mathrm{C}+\mathrm{NT}}$ and $\mathrm{R}_{\mathrm{NT}}$ cannot be due to any increased measurement distance since the probe separation is much greater than the difference in the measurements for $\mathrm{R}_{\mathrm{C}+\mathrm{NT}}$ and $\mathrm{R}_{\mathrm{NT}}$. For example, as seen in Fig. $4 \mathrm{a}$ and $\mathrm{b}$, the probe separation for $\mathrm{R}_{\mathrm{C}+\mathrm{NT}}$ and $\mathrm{R}_{\mathrm{NT}}$ is $9.56 \mu \mathrm{m}$ and $9.2 \mu \mathrm{m}$ respectively. This $3 \%$ increase in probe separation cannot account for the difference in $\mathrm{R}_{\mathrm{C}+\mathrm{NT}}$ and $\mathrm{R}_{\mathrm{NT}}$ observed (6.6 $\Omega$ ). Thus, the variation must be due to differences in the junction resistance between the catalyst cap and the MWCNT.

Fig. 5 shows a plot of $\mathrm{D}_{\mathrm{C}} / \mathrm{D}_{\mathrm{NT}}$ ratio versus $\mathrm{R}_{\mathrm{C}+\mathrm{NT}} / \mathrm{R}_{\mathrm{NT}}$ ratio and reveals an inverse nonlinear relationship. As $\mathrm{D}_{\mathrm{C}}$ increases, relative to $\mathrm{D}_{\mathrm{NT}}$, the difference in the $\mathrm{R}_{\mathrm{C}+\mathrm{NT}}$ compared to $\mathrm{R}_{\mathrm{NT}}$ decreases. Alternatively, the relationships between diameter and resistance ratios can be divided into two regimes. First, is where the diameter of the catalyst is larger than the diameter of the associated MWCNT $\left(\mathrm{D}_{\mathrm{C}}>\mathrm{D}_{\mathrm{NT}}\right)$ then the resistance through the catalyst approaches that of the MWCNT, i.e., $\mathrm{R}_{\mathrm{C}+\mathrm{NT}} \approx \mathrm{R}_{\mathrm{NT}}$. Second, is when the diameter of the catalyst is smaller than the diameter of the associated MWCNT $\left(\mathrm{D}_{\mathrm{C}}<\mathrm{D}_{\mathrm{NT}}\right)$ then the resistance through the catalyst is much larger than that of the MWCNT, i.e., $\mathrm{R}_{\mathrm{C}+\mathrm{NT}}>>\mathrm{R}_{\mathrm{NT}}$.

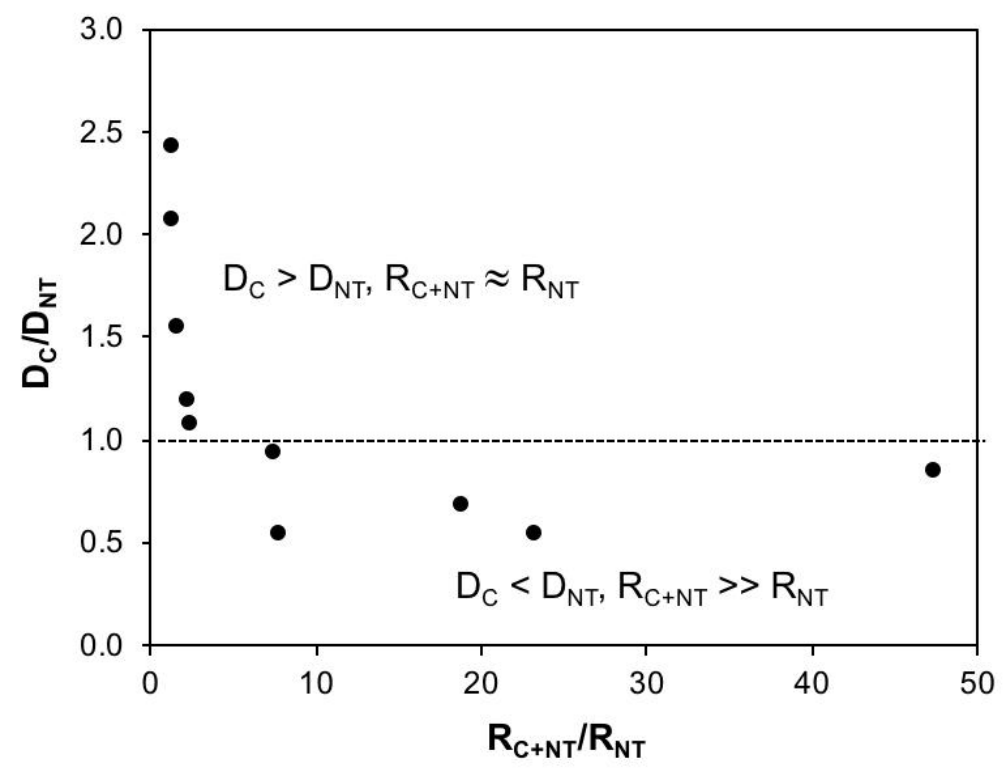

Fig. 5 Plot of the ratio of the diameters of the catalyst $\left(D_{C}\right)$ to the MWCNTs $\left(D_{N T}\right)$ against ratio of the resistance through the catalyst and MWCNTs $\left(\mathrm{R}_{\mathrm{C}+\mathrm{NT}}\right)$ to through the MWCNTs only $\left(\mathrm{R}_{\mathrm{NT}}\right)$. The dashed line represents $\mathrm{D}_{\mathrm{C}}=\mathrm{D}_{\mathrm{NT}}$.

To understand if the increased resistance is caused by barrier formation, we have analysis the I-V curves and representative examples are shown in Fig. 6. To directly compare 
the shape of the I-V curve the current has be normalized to the current measured at $+1 \mathrm{~V}$. The $\mathrm{I}-\mathrm{V}$ curve taken for the MWCNTs alone (i.e., where both probes are on the MWCNT) are close to ohmic in nature (black lines in Fig. 6). For cases where the $D_{c}>D_{N T}$ there is little shift in the shape of the curve (e.g., Fig. 6a and b) suggesting the catalyst $\cdots$ MWCNT contact is ohmic. For cases where $\mathrm{D}_{\mathrm{C}}<\mathrm{D}_{\mathrm{NT}}$, the I-V curve shift to more rectifying. It also appears that as $\mathrm{D}_{\mathrm{C}} / \mathrm{D}_{\mathrm{NT}}$ decreases the interface between the catalyst and the nanotube becomes more rectifying (see Fig. $6 \mathrm{c}$ versus Fig. 6d). A simple quantification of this can be calculated by finding the average difference between the normalized currents at each voltage. For the curves shown in Fig. 6a and $b$ this valve was calculated to be 0.007 and 0.012 respectively while for the curves in Fig. $6 \mathrm{c}$ and $\mathrm{d}$ it was calculated to be 0.116 and 0.133 . Considering all the samples measured it appear from Fig 7 that shows that there is shift in the nature of transport mechanism from near ohmic to rectifying when the catalyst diameter is smaller than the nanotube diameter.

a)

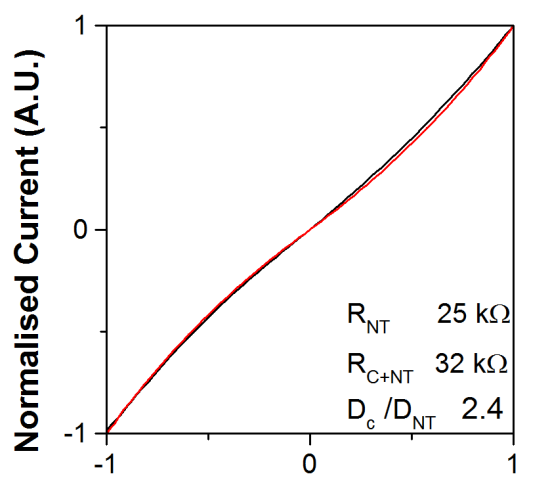

c)

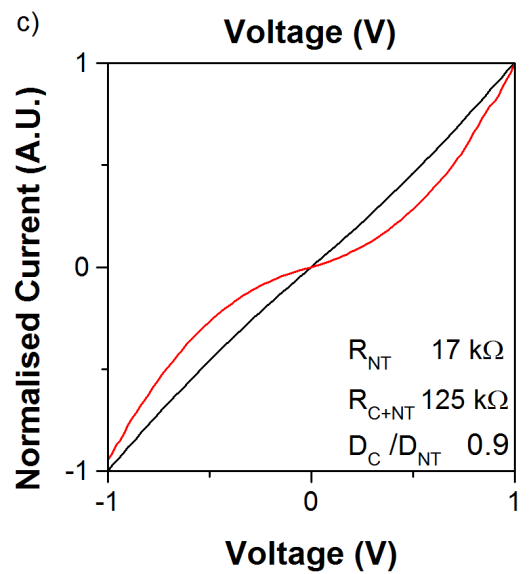

b)
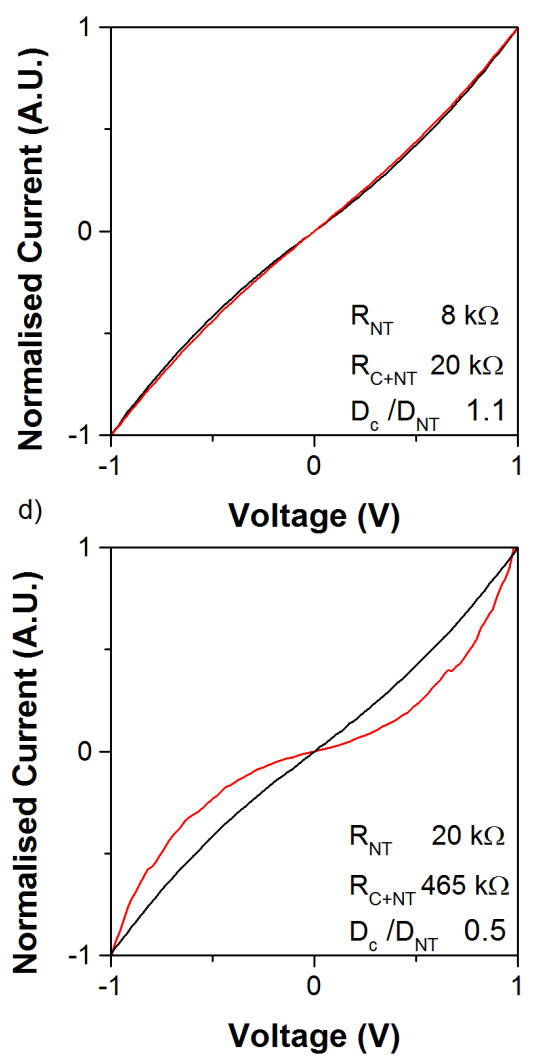

Fig. 6 Plots of normalized IV curves for transport through the MWCNT (black line) and through catalyst cap and MWCNT on the same MWCNT (red line) with $\mathrm{D}_{\mathrm{C}} / \mathrm{D}_{\mathrm{NT}}$ equal to (a) 2.4, (b) 1.1 , (c) 0.9 and (d) 0.5 . The text boxes show the measured resistances at $-1 \mathrm{~V}$ and the diameters of the MWCNT and catalyst. 


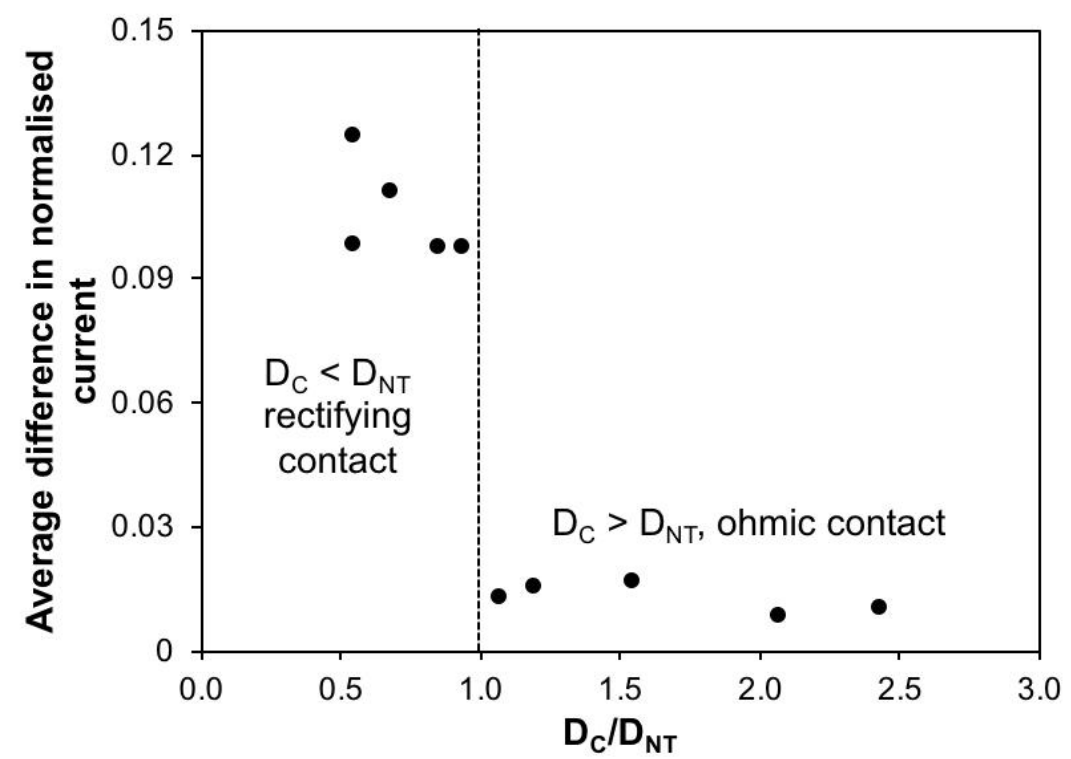

Fig. 7 Plots of average difference in normalized current curves against ratio of the diameters of the catalyst $\left(\mathrm{D}_{\mathrm{C}}\right)$ to the MWCNTs $\left(\mathrm{D}_{\mathrm{NT}}\right)$.

The forgoing results show that the absolute size of catalyst $\left(\mathrm{D}_{\mathrm{C}}\right)$ per se does not dictate the conduction mechanism into the nanotube, but rather that $\mathrm{D}_{\mathrm{C}} / \mathrm{D}_{\mathrm{NT}}$ is the controlling parameter. It is difficult to attribute the observation to a single effect, however, a study by Lord et al. on $\mathrm{ZnO}$ nanowires with gold catalyst caps reports similar results [22]. Using comparable nanoscale 2-point-probe measurements they observed that when the ratio in diameter of the catalyst cap to $\mathrm{ZnO}$ nanowire fell below a certain value, the measure I-V curve became rectifying in nature. Through modelling they found that when the catalyst cap is small compared the $\mathrm{ZnO}$ nanowire diameter electrons experience a higher electric field at the contact, an effect call "current crowding" which effectively creates a rectifying barrier to electron transport from the catalyst into the nanostructure. We attribute our observation reported here to the same effect of current crowding at the junction of catalyst and nanostructure. Although $\mathrm{ZnO}$ and carbon have very different electrical properties, it would appear than the effect observed here is attribute to the property's cylindrical nanostructure in combination with the catalyst caps, and not the nature of the material's property. It would appear to be therefore independent of composition, however, modelling or comparison with other systems is needed to confirm this conclusion.

\section{Conclusion}


In this study, we have carried out nanoscale 2-point-probe on MWCNTs and compared the measured I-V characteristic and resistance to transport through an iron catalyst residue cap on the end of the MWCNT. We observed a relationship between the ratio the diameters of the tubes and catalyst caps and the transport mechanism across the interface. When the catalyst cap diameter is smaller than the nanotube diameter the I-V characteristic are rectifying in nature and the barrier to transport, which we attribute to "current crowding", results in high resistance measurements and is structure dependent rather than material dependent. The work presented here suggests that if end to end contact are to be made to increase the length MWCNTs fibers, then the larger catalyst caps with large diameter than the nanotubes are desirable. Furthermore, if it becomes possible to control the ratio of the catalyst diameter to nanotube diameter, then our work suggest that is would be possible to use the catalyst caps as contacts in nanoscale devices with contact type being varied between ohmic and rectifying depending on application needs.

\section{Acknowledgments}

Financial support was provided by the Flexible Integrated Energy Systems (FLEXIS) operations funded by the Welsh European Funding Office (WEFO) through the Welsh Government and the Office of Naval Research (N00014-15-2717). The Welsh Government is also acknowledged for Sêr Cymru II Fellowships (A.O.W) part funded by the European Regional Development Fund (ERDF).

\section{Conflict of interests}

On behalf of all authors, the corresponding author states that there is no conflict of interest.

\section{References}

1. Kumar M, Yoshinori A (2010) Chemical vapor deposition of carbon nanotubes: a review on growth mechanism and mass production. J Nanosci Nanotechnol 10:3739.

2. Orbaek AW, Aggarwal N, Barron AR (2013) The development of a 'process map' for the growth of carbon nanomaterials from ferrocene by injection CVD. J Mater Chem A 1:14122.

3. Gohier A, Ewels CP, Minea TM, Djouadi MA (2008) Carbon nanotube growth mechanism switches from tip- to base-growth with decreasing catalyst particle size. Carbon 47:1331. 
4. Gomez V, Irusta S, Adams WW, Hauge RH, Dunnill CW, Barron AR (2016) Enhanced carbon nanotubes purification by physic-chemical treatment with microwave and $\mathrm{Cl}_{2}$. $\mathrm{RSC}$ Adv 6:11895.

5. Zhang KS, Pham D, Lawal O, Ghosh S, Gangoli VS, Smalley P, Kennedy K, Brinson B, Billups WE, Hauge R, Adams WW, Barron AR (2017) Overcoming catalyst residue inhibition of the functionalization of single-walled carbon nanotubes via the Billups-Birch reduction. ACS Appl Mater Interfaces 9:37972.

6. Stobinski L, Lesiak B, Kövér L, Tóth J, Biniak S, Trykowski G, Judek J (2010) Multiwall carbon nanotubes purification and oxidation by nitric acid studied by the FTIR and electron spectroscopy methods. J. Alloy. Compd 501:77.

7. $\mathrm{Hu} \mathrm{H}$, Zhao B, Itkis ME, Haddon RC (2003) Nitric acid purification of single-walled carbon nanotubes. J Phys Chem B 107:13838.

8. Silvestre N (2013) State-of-the-art review on carbon nanotube reinforced metal matrix composites. Int J Compos Mater 3:28.

9. Barnett CJ, McCormack JE, Deemer EM, Evans C, Evans JE, Orbaek White A, Dunstan PR, Chianelli RR, Cobley RJ, Barron AR (2020) Enhancement of multiwalled carbon nanotubes' electrical conductivity using metal nanoscale copper contacts and its implications for carbon nanotube-enhanced copper conductivity. J Phys Chem C 124:18777.

10. Matsuda Y, Deng W-Q, Goddard III WA (2010) Contact resistance for "end-contacted" metal-graphene and metal-nanotube interfaces from quantum mechanics. J Phys Chem C 114: 17845 .

11. Barnett CJ, Gowenlock CE, Welsby K, Orbaek White A, Barron AR (2018) Spatial and contamination-dependent electrical properties of carbon nanotubes. Nano Lett 18:695.

12. Barnett CJ, Evans C, McCormack JE, Gowenlock CE, Dunstan P, Orbaek White A, Barron AR (2019) Experimental measurement of angular and overlap dependence of conduction between carbon nanotubes of identical chirality and diameter. Nano Lett 19:4861.

13. Gangoli VS, Raja PMV, Esquenazi GL, Barron AR (2019) The safe handling of bulk lowdensity nanomaterials. SN Appl. Sci. 1:644.

14. Ibe JP, Bey Jr PP, Brandow SL, Brizzolara RA, Burnham NA, DiLella DP, Lee KP, Marrian CRK, Colton RJ (1990) On the electrochemical etching of tips for scanning tunneling microscopy. J Vac Sci Technol A 8:3570. 
15. Cobley RJ, Brown RA, Barnett CJ, Maffeis TGG, Penny MW (2013) Quantitative analysis of annealed scanning probe tips using energy dispersive X-ray spectroscopy. Appl Phys Lett 102:3.

16. Barnett CJ, Kryvchenkova O, Wilson LSJ, Maffeis TGG, Kalna K, Cobley RJ (2015) The role of probe oxide in local surface conductivity measurements. J Appl Phys 117:174306.

17. Smith NA, Lord AM, Evans JE, Barnett CJ, Cobley RJ, Wilks SP (2015) Forming reproducible non-lithographic nanocontacts to assess the effect of contact compressive strain in nanomaterials. Semicond Sci Technol 30:065011.

18. Li Y, Kim W, Zhang Y, Rolandi M, Wang D, Dai H (2001) Growth of single-walled carbon nanotubes from discrete catalytic nanoparticles of various sizes. J Phys Chem B $105: 11424$.

19. Ding F, Rosén A, Bolton K (2004) Molecular dynamics study of the catalyst particle size dependence on carbon nanotube growth. J Chem Phys 121:2775.

20. Cheung CL, Kurtz A, Park H, Leiber CM (2002) Diameter-controlled synthesis of carbon nanotubes J Phys Chem B 106:2429.

21. Ogrin D, Colorado Jr. R, Maruyama B, Pender MJ, Smalley RE, Barron AR (2006) Singlewalled carbon nanotube growth using $\left[\mathrm{Fe}_{3}\left(\mu_{3}-\mathrm{O}\right)\left(\mu-\mathrm{O}_{2} \mathrm{CR}\right)_{6}(\mathrm{~L})_{3}\right]^{\mathrm{n}+}$ complexes as catalyst precursors. Dalton Trans 2006:229.

22. Lord AM, Maffeis TG, Kryvchenkova O, Cobley RJ, Kalna K, Kepaptsoglou DM, Ramasse QM, Walton AS, Ward MB, Köble J, Wilks SP (2015) Controlling the electrical transport properties of nanocontacts to nanowires. Nano Lett 15:4248. 
Graphical Abstract

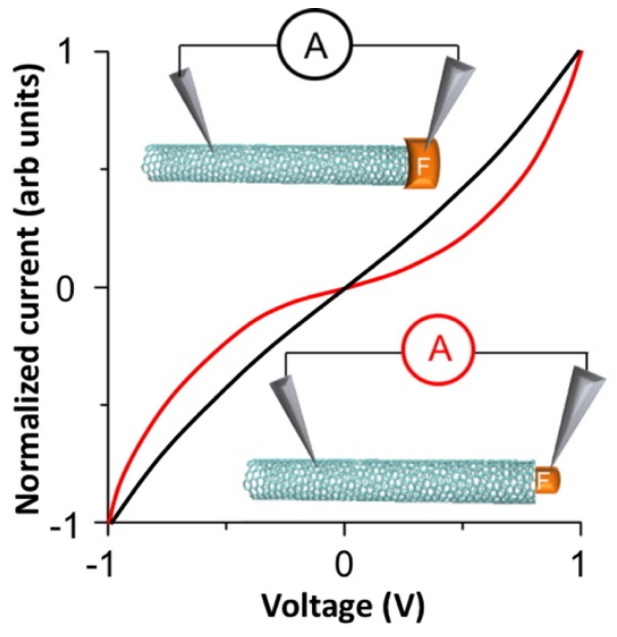

